\title{
FILOSOFÍA DE LA EDUCACIÓN.COM: MANUAL DE TRABAJO
}

\author{
Lourdes Lavaniegos* \\ lourdeslavaniegos@yahoo.com.mx
}

López Calva, Martín

Trillas, 2008

Martín López Calva parte para la creación de esta obra de la experiencia vivida en una cátedra universitaria acerca de la filosofía de la educación.

Considera que la filosofía es capaz de suscitar una reflexión profunda en quienes la estudian, y en consecuencia propone ejercicios que per- siguen un aprendizaje significativo mediante la dinámica de grupo y las preguntas trascendentales de la filosofía.

El libro está diseñado para utilizarse con grupos de educadores, así que las cuestiones que se analizan se enfocan a la reflexión y mejoramiento de la práctica educativa.

Se propone una clara metodología constructivista que inicia cada sección con ejercicios de reflexión personal que paulatinamente van compartiéndose mediante juegos para llegar a una metacognición socializada que bien puede servir como base para comprender la riqueza del trabajo interdisciplinario y de academia.

El diseño de la obra es ingenioso porque toma el formato de una página virtual que posiblemente resulte llamativo para las jóvenes generaciones apegadas al mundo cibernético.

El contenido se presenta en nueve capítulos que van compaginando los aspectos esenciales de la filosofía con las experiencias de vida de los participantes. Comienzan con una actividad de inducción, incluyen una lectura y terminan sugiriendo dinámicas interactivas para la aplicación de los conceptos descubiertos a la vida cotidiana.

El primer capítulo se dedica a encuadrar el curso, aspecto que resulta importante para que los participantes comprendan su papel dentro del curso que está diseñado a modo de taller. Señala los objetivos del texto, los contenidos básicos, y da instrucciones para la implementación de la metodología sugerida: actividades, lecturas y reflexión.

El segundo capítulo se dedica a la presentación de los conceptos de filosofía y de educación buscando las relaciones entre ambos; para ello realiza una comparación con lo que suele ocurrir en las páginas electrónicas y las ligas entre ellas. Para la aplicación a la vida cotidiana se incluyen referencias al trabajo de Mathew Lipman y 
su "Filosofía para Niños" y una explicación sobre el método "PEACE" de Marinoff para el asesoramiento filosófico.

Como tercer tema se tratan las ramas de la filosofía y sus ámbitos de reflexión y las principales corrientes filosóficas y sus aportaciones e in- fluencias para el campo educativo. El análisis de cada corriente culmina con la interesante propuesta de un lema que sintetiza su forma de ver la vida y resulta un claro mecanismo de memorización a través de la comprensión.

Dedicado ya directamente a la filosofía de la educación, el cuarto capítulo simula un recorrido por un bulevar: avenidas que cruzan monumentos y hasta un acueducto van simbolizando el camino recorrido por los teóricos que han influido en el proceso de conformación de la práctica educativa a lo largo de la historia, desde sus orígenes hasta la post- modernidad. Termina con la pregunta “¿Qué sigue?”, la cual invita a la reflexión del lector.

Habiendo abordado los conceptos fundamentales, el capítulo quinto se dedica a la evaluación de lo aprendido en los capítulos anteriores con un formato muy completo, dividido en cuatro partes: la primera busca datos, la segunda intelecciones, la tercera reflexión crítica y la cuarta valoración.

El siguiente tema se dedica a comprender la evolución de la filosofía de la educación a partir del estudio de sus principales protagonistas. Prácticamente no existen contenidos, salvo las sugerencias metodológicas. El reconocimiento de cada personaje se verifica de manera anecdótica y al final se pide al lector que reflexione sobre los aspectos en que se identifica con él.

Una nueva evaluación de lo aprendido en cuatro fases: datos, comprensión, análisis y fundamentación, y síntesis integran el séptimo capítulo.

El octavo capítulo se dedica a la comprensión de la influencia que han tenido las diferentes corrientes filosóficas sobre la educación y para ello se propone una "Feria de refranes y frases publicitarias".

Por último, el noveno capítulo trata sobre temas actuales de la filosofía de la educación como son: sustentabilidad, religión, equidad, tecnología y otros.

En las conclusiones, López Calva recuerda las preguntas fundamentales de la filosofía: ¿Qué es el hombre? ¿Qué puede esperar? Y ¿Qué puede hacer para lograr lo que espera? y califica su propia obra como una forma de inquietar al lector y despertar su sed de reflexión.

"Filosofía de la educación. com" no puede considerarse un compendio exhaustivo de la filosofía de la educación, se acerca más a ser un remojo en los principales conceptos filosóficos. Parece no importar que algunos conceptos se traten con ligereza ya que su mayor preocupación es que aquéllos que se traten sean comprendidos y reflexionados a profundidad.

Los libros de filosofía normalmente pueden usarse como almanaques en los que se 
encuentra un contenido estructurado de manera formal, la obra que nos ocupa, en cambio, deja a los contenidos al servicio de la comprensión y de la vivencia de la propia filosofía; resulta como consecuencia un elemento totalmente apegado al enfoque constructivista que desde su prólogo anuncia.

El formato de manual lo hace muy apropiado para grupos de estudio, especialmente para jóvenes hábiles para comprender las riquezas de la estructura de una página virtual. Puede resultar útil para todo grupo que se dedique a los análisis de la realidad, especialmente educadores en formación y padres de familia en búsqueda de criterios para dirigir su estilo educativo. 